\title{
Vascular Inflammation and Endothelial Dysfunction in Experimental Hypertension
}

\author{
Carmine Savoia, ${ }^{1}$ Lidia Sada, ${ }^{1}$ Luigi Zezza, ${ }^{1}$ Lorenzo Pucci, ${ }^{1}$ Francesco Maria Lauri, ${ }^{1}$ \\ Alberto Befani, ${ }^{1}$ Alessandro Alonzo, ${ }^{1}$ and Massimo Volpe ${ }^{1,2}$ \\ ${ }^{1}$ Cardiology Unit, Clinical and Molecular Medicine Department, Sant'Andrea Hospital, Sapienza University of Rome, \\ Via di Grottarossa 1037/1039, 00189 Rome, Italy \\ 2 IRCCS Neuromed, Polo Molisano University of Rome La Sapienza, Pozzilli, Italy
}

Correspondence should be addressed to Carmine Savoia, savoiac@yahoo.it

Received 5 May 2011; Accepted 12 July 2011

Academic Editor: Thomas Unger

Copyright (C) 2011 Carmine Savoia et al. This is an open access article distributed under the Creative Commons Attribution License, which permits unrestricted use, distribution, and reproduction in any medium, provided the original work is properly cited.

Essential hypertension is characterized by increased peripheral vascular resistance to blood flow. The endothelium is a crucial regulator of vascular tone. Its function is impaired in patients with hypertension, with reduced vasodilation, increased vascular tone associated with a proinflammatory and prothrombotic state. Low-grade inflammation localized in vascular tissue is therefore recognized as an important contributor to the pathophysiology of hypertension, to the initiation and progression of atherosclerosis as well as to the development of cardiovascular diseases.

\section{Introduction}

Vascular remodeling and increased peripheral vascular resistance to blood flow are common features of essential hypertension. Resistance arteries may play an important role in the development [1] and may contribute to the complications of hypertension [2]. Small decrease in the lumen of the small arteries significantly increases resistance to blood flow. Vascular tone is regulated by the endothelium, which may affect vascular function and remodeling. Endothelium is the active inner monolayer of the blood vessels, forming an interface between circulating blood and the vessel wall. It represents the largest organ in the body and plays a critical role in vascular homeostasis. Endothelial cells regulate vascular tone by releasing various contracting and relaxing factors including nitric oxide (NO), arachidonic acid metabolites, reactive oxygen species (ROS), and vasoactive peptides. Therefore, the endothelium actively regulates vascular tone and permeability, the balance between coagulation and fibrinolysis, the inflammatory activity as well as cell proliferation. Endothelial dysfunction is characterized by impaired vasomotor response (reduced vasodilation and increased endotheliumdependent contraction), cell proliferation, platelet activa- tion, vascular permeability, and a proinflammatory and prothrombotic phenotype, including leucocyte-endothelial interactions that participate in vascular inflammation and increased adhesion and aggregation of platelets [3].

Endothelial progenitor cells (EPCs), a bone-marrowderived population of cells which can develop into competent mature endothelial cells [4], are seen as an important determinant of endothelial function. Decreased EPCs number is associated with arterial stiffness [4] and decreased endothelial function [5]. In this regard, it has been shown that circulating EPCs are significantly reduced in hypertensive type 2 diabetic patients [4] and in salt-loaded hypertensive rats [5].

Endothelial dysfunction occurs in association with several cardiovascular risk factors. Hypercholesterolemia, hypertension, and insulin resistance contribute to endothelial dysfunction and inflammation in the vascular wall, as well as to increased lipoprotein oxidation, smooth muscle cell proliferation, extracellular matrix deposition, cell adhesion, and thrombus formation [6-8]. Thus, endothelial dysfunction may be involved in the initiation of vascular inflammation, in the development of vascular remodeling, it is an early determinant in the progression to atherosclerosis, and it is 
independently associated with increased cardiovascular risk [9-12].

Endothelial dysfunction promotes vascular inflammation by inducing the production of vasoconstrictor agents, adhesion molecules, and growth factors including angiotensin II (Ang II) and endothelin $1[6,8]$. Ang II, one of the final products of the renin-angiotensin system (RAS), is actively involved in the pathophysiology of hypertension [13]. It may be responsible for triggering endothelial dysfunction and vascular inflammation by inducing oxidative stress, resulting in upregulation of inflammatory mediators and cell-growth.

Low-grade inflammation in the vascular wall is an important contributor to the pathophysiology of hypertension [14], atherosclerosis, and the development of cardiovascular disease (CVD) $[11,15]$. Patients with CVD present with increased expression and plasma concentration of inflammatory markers and mediators [16, 17]. In particular, increased plasma levels of TNF-a (tumour necrosis factor-a), IL (interleukin)-6, as well as the adhesion molecules ICAM1 (intercellular adhesion molecule-1), VCAM-1 (vascular cell adhesion molecule-1), and E-selectin, as well as vWF (von Willebrand factor) and CRP (C-reactive protein), have been demonstrated [18-20] in hypertensive subjects. Thus inflammation is a central mechanism contributing to the progression of CVD, and may be involved in the triggering of myocardial and cerebrovascular ischemia $[8,21]$.

In this paper we discuss the role of the low-grade inflammation in the vascular pathology in experimental hypertension.

\section{Low-Grade Inflammation and Endothelial Dysfunction in Vascular Pathology}

Blood pressure itself or RAS activation [16] may induce the inflammatory process, which participates to vascular remodeling and may contribute to accelerated vascular damage in aging and CVD. Endothelial dysfunction is an early determinant in the development of hypertension, in the progression to atherosclerosis and is independently associated with increased cardiovascular risk [9]. Essential hypertension is characterized by increased peripheral vascular resistance to blood flow, which occurs mostly as a result of energy dissipation in small resistance arteries, particularly in younger individuals. Enhanced constriction of resistance arteries may increase peripheral resistance in hypertension by reducing lumen diameter [22]. Endothelial dysfunction may participate to the increased vascular tone in hypertension [10], with reduced vasodilation associated with a proinflammatory and prothrombotic state. Moreover, in hypertension, resistance arteries undergo vascular remodeling (reduced lumen with increased media width) that may be structural, mechanical, or functional. Extracellular matrix deposition and inflammation are critically involved in vascular remodeling. With chronic vasoconstriction (due to increased myogenic tone, RAS activation, catecholamines, and growth factors production), vessels may become embedded in the remodeled extracellular matrix and may not return to their vasodilated state [23]. Chronically elevated blood pressure and stretch induce complex signal transduction cascades leading to vascular remodeling that contributes not only to elevation of blood pressure but also to hypertensive complications [24]. Arterial hypertension as well as aging and other cardiovascular risk factors may also increase arterial stiffness in large conduit arteries, which is associated with both target organ damage and increased risk for cardiovascular morbidity and mortality [25]. Inflammation of large arteries exerts its effects in part by contributing to endothelial dysfunction and by increasing vascular stiffness, in the presence or absence of hypertension.

Inflammation contributes to vascular remodeling promoting cell growth and proliferation of vascular smooth muscle cells (VSMCs). This is supported by the increased expression in the vascular wall of adhesion molecules and ligands, leukocyte extravasation, increased oxidative stress, cytokine production, activation of immune cells and proinflammatory signaling pathways. Greater expression of adhesion molecules (VCAM-1, ICAM-1) on the endothelial cell membrane, accumulation of monocyte/macrophages, dendritic cells, natural killer cells, and B and T lymphocytes participate to the inflammatory response in the vascular wall [26]. Patients with CVD present increased expression and plasma concentration of inflammatory markers and mediators [17, 21, 27]. High levels of inflammatory mediators (IL-6, ICAM-1, and CRP) may be independent risk factors for the development of hypertension [18, 19]. Moreover they have been associated with increased risk of diabetes [20] and CVD. In particular CRP measured with a high-sensitivity assay (hsCRP) has been related to insulin resistance, systolic blood pressure, pulse pressure (PP, an index of arterial stiffness) $[28,29]$, and to markers of endothelial dysfunction including plasma levels of vWF, tissue plasminogen activator and cellular fibronectin [30]. Plasma hsCRP level is a strong predictor of ischemic cardiovascular events in patients with stable or unstable angina; it correlates with vulnerable plaques, and it may as well predict cardiovascular events among apparently healthy subjects [31-33].

Innate immunity may play a role in the mechanisms that contribute to the low-grade inflammatory response in hypertension. In mice deficient in vascular macrophages (due to a mutation in the mCSF gene) Ang II and deoxycorticosterone acetate-(DOCA-) salt were not able to induce hypertension or vascular remodeling [14]. Moreover, mice deficient in $T$ and B lymphocytes presented blunted hypertensive response to Ang II and DOCA-salt [34]. Reduced vascular remodeling in response to Ang II was also observed [34]. The lack of response to Ang II was corrected by effector $\mathrm{T}$ cell but not by B lymphocyte adoptive transfer. Moreover, the central and pressor effects of Ang II are critical for T-cell activation and the development of vascular inflammation [35]. T lymphocytes may participate in hypertension and peripheral inflammation possibly by the increased production of oxidative stress [36]. A role of T regulatory (Treg) lymphocytes in blood pressure regulation and vascular inflammation has also been described. It has been recently shown that Treg adoptive transfer lowered blood pressure and protected from vascular remodeling in mice infused with 
either Ang II or aldosterone. It has been recently showed that adoptive immunity may be enhanced as a result of a genetic predisposition with loci on chromosome 2 (which carries many pro-inflammatory genes) [37] in a consomic strain of rats (SSBN2), which contains the genetic background of hypertensive Dahl salt-sensitive rats and chromosome 2 from Brown-Norway normotensive rats. The presence of the normotensive chromosome 2 was associated with upregulation of Treg markers (CD8+ and CD4+ lymphocytes which were CD25+). Those markers were depressed in the Dahl salt-sensitive rats. Enhanced Treg and increased expression of the transcription factor Foxp3 (a marker of Treg) as well as IL-10 and TGF (transforming growth factor)beta production (produced by Treg) were found in consomic rats and the opposite in Dahl rats. The potential protective role of Treg in cardiovascular disease is further supported by the evidence that adoptive transfer of Treg cells ameliorated cardiac damage and improved eutrophic remodeling in Ang II-infused mice, independently of blood-pressure-lowering effects [27]. This suggests a role of Treg in the pathogenesis of blood-pressure-induced cardiovascular remodeling. Hence, different subsets of $\mathrm{T}$ lymphocytes may be involved in the mechanisms leading to the inflammatory response described in cardiac and metabolic diseases when an imbalance exists between the pro-inflammatory Th1, Th2, and Th17 and the antiinflammatory Treg subsets [27].

\section{Role of Renin-Angiotensin System in Vascular Damage}

Ang II plays a key role in the pathophysiology of hypertension [24] and CVD by inducing vascular remodeling and injury. Several mechanisms may be activated by Ang II such as endothelial dysfunction, vasoconstriction, cell growth, oxidative stress, and inflammation. Ang II stimulates cell growth by inducing hyperplasia and hypertrophy of VSMCs from resistance arteries of patients with essential hypertension and from small arteries of hypertensive rats.

In hypertension, Ang II may enhance basal superoxide production in the vasculature by activation of reduced NADPH (Nicotinamide Adenine Dinucleotide Phosphate) oxidase and expression of its subunits via cSrc, PKC (Protein Kinase C), PLA 2 (Phospholipase $\mathrm{A}_{2}$ ), and PLD (Phospholipase D) pathways [38-41]. These processes may contribute to increased activation of NADPH oxidase and, in turn, to enhanced oxidative stress in the vascular wall [10]. NADPH oxidase is the major source of ROS in the vascular wall. It is expressed in endothelial cells, VSMCs, fibroblasts, and monocytes/macrophages $[42,43]$. Increased Ang II-induced ROS generation is involved in the process of vascular remodeling. This occurs by VSMC proliferation and hypertrophy, collagen deposition, and by modulating cytokine release and pro-inflammatory transcription factors. ROS activate multiple signaling molecules including mitogen-activated protein kinases (MAP-kinases); nonreceptor tyrosine kinases such as Src, JAK-2 (Janus Kinase 2), STAT (Signal Transducer and Activator of Transcription), p21Ras, Pyk-2 (Proline-rich Tyrosine Kinase 2), and Akt; receptor tyrosine kinases (EGFR
(Epidermal Growth Factor Receptor), IGFR (Insulin-like Growth Factor Receptor 1), and PDGFR (Platelet-Derived Growth Factor Receptor); protein tyrosine phosphatases and redox-sensitive transcriptor factors (Nuclear Factor $(\mathrm{NF})-\kappa \mathrm{B}$, Activator Protein 1 (AP)-1 and Hypoxia-inducible factor 1 (HIF-1)) [42, 44]. Thus, ROS act as signaling molecules, modulating vascular tone and structural changes in the vasculature [39] and participate in the development and progression of atherosclerosis [44]. In addition, ROS reduce the vascular bioavailability of NO $[45,46]$ which is associated with impaired endothelium-dependent vascular relaxation and increased vascular contractile responses. Moreover this is also associated to structural changes in the wall of small arteries and to the increased peripheral vascular resistance [47]. Ang II-induced ROS production increases ICAM-1 expression, macrophage infiltration, monocyte chemotactic protein (MCP)-1 production, and vascular hypertrophy, independently of blood pressure elevation [48]. Furthermore Ang II stimulates the production of E-selectin through redox-dependent pathways [48] and PAI-1, which contributes to a prothrombotic state as well as to atherosclerotic plaque rupture. Moreover, macrophages which infiltrate the adventitia or the media of blood vessels may generate oxidative stress by NADPH oxidase $[48,49]$.

Ang II-induced growth and profibrotic effects are partially modulated by endogenous production of mitogenic factors (including TGF- $\beta$, PDGF (platelet-derived growth factor), EGF (epidermal growth factor), IGF-1 (insulin-like growth factor 1) and endothelin-1) $[50,51]$. In particular TGF- $\beta$ is produced by macrophages, lymphocytes, fibroblasts, VSMCs and is overexpressed in many cardiovascular and renal disorders associated with activation of the RAS. TGF- $\beta$ increases extracellular matrix biosynthesis, downregulates matrix degradative enzymes, and influences integrin receptors [52, 53]. p38MAP kinase and connective tissue growth factor are among the major downstream profibrogenic mediators of TGF- $\beta$. Inhibition of the RAS with ACE inhibitors or ARBs is directly correlated with suppression of TGF- $\beta$ production and amelioration of fibrosis $[52,54]$.

Inflammation may activate the RAS, which in turn may further contribute to vascular remodeling in hypertension. Activators of nuclear receptors, such as the peroxisome proliferator-activated receptors (PPARs), downregulate the vascular inflammatory response in experimental animals [55] and decrease serum markers of inflammation in humans [56]. Hence, PPARs may be endogenous modulators of the inflammatory process involved in vascular structural changes in hypertension. On the other hand, Ang II downregulates PPARs through activation of NF- $\kappa \mathrm{B}$ [57].

Ang II may also play a role in EPC production. This effect may be dependent on the duration of Ang II exposure [58]. Acute Ang II administration via $\mathrm{AT}_{1} \mathrm{R}$ synergistically increases vascular endothelial growth factor-(VEGF-) induced proliferation of EPCs [59]. Moreover, in Ang IIinfused mice or in a clipped kidney mouse model of hypertension, the number of circulating EPCs increased. This may be dependent on an increase in cell proliferation as well as on a reduction in apoptosis via Akt and eNOS-derived NO production [60]. $\mathrm{AT}_{1} \mathrm{R}$ antagonism blocked this effect [61]. On 
the other hand, it has been also shown that Ang II decreases EPC number. Infusion of Ang II in rats is associated with decreased EPC number that is reversible by treatment with an $\mathrm{ARB}$ [62]. $\mathrm{AT}_{1} \mathrm{R}$ blockade increased EPC numbers in type 2 diabetic patients [5]. Infusion of Ang II in rats significantly reduced telomerase activity and accelerated the onset of cellular senescence in EPCs, suggesting that reduction in EPC levels after Ang II infusion results from impaired EPC proliferation. Studies in cultured EPCs suggest that the mechanism of Ang II-mediated EPC senescence may also involve ROS [63]. In these cells, the induction of EPC senescence was found to be associated with NADPH oxidase-dependent generation of ROS. Indeed, treatment with superoxide dismutase (SOD) blocked Ang II-mediated EPC senescence.

ROS are potent stimulators of endothelin-1 synthesis by endothelial cells and VSMCs [64]. Endothelin-1 in turn activates NADPH oxidase as well as other sources of ROS, such as xanthine oxidase and mitochondria, in VSMCs and blood vessels [65-67]. Moreover, Ang II-induced inflammation via NF- $\kappa$ B and AP- 1 activation involves in part endothelin receptors [68]. Endothelin-1-induced oxidative stress promotes inflammatory responses and in turn contributes to the vascular remodeling and endothelial dysfunction in animal models of hypertension that present an endothelinmediated component [69]. $\mathrm{ET}_{\mathrm{A}}$ (Endothelin A) receptor antagonism decreases oxidative stress, normalizes hypertrophic remodeling, decreases collagen and fibronectin deposition, and reduces adhesion molecules in the vasculature of aldosterone-infused rats [70]. Endothelial dysfunction and increased activity of NADPH oxidase were described [68] in mice overexpressing preproendothelin-1 in the endothelium. This was associated with enhanced oxidative stress and vascular inflammation [68] and, in turn, to increased arterial stiffness as well as to increased collagen deposition, independently of blood pressure [68]. In humans, exogenous endothelin-1 has also been shown to increase arterial stiffness $[71,72]$. Hence, in endothelial dysfunction where NO is downregulated and endothelin-1 upregulated, the balance is shifted in favor of increased arterial stiffness.

Ang II induces aldosterone synthesis which in turn increases tissue ACE activity [73] and up-regulates angiotensin receptors [74]. The activation of mineralocorticoid receptors may contribute to cardiovascular dysfunction, inflammation, fibrosis, and vascular damage. Several animal models have confirmed that aldosterone may induce ROS formation and endothelial dysfunction, and therefore it can cause injury of the vasculature of the brain, heart, and kidneys [75]. Endothelial dysfunction and inflammation induced by aldosterone may involve the activation of COX-2 (cyclooxygenase-2) in normotensive and hypertensive rats [76]. Mineralocorticoid antagonism attenuates the aldosterone-induced damage by reducing the direct proinflammatory and pro-fibrotic effects of aldosterone that may be mediated via activation of the endothelin system [70, 77-79]. Mineralocorticoid receptor blockade may also improve endothelial function and reduce oxidative stress in Ang II-infused rats [80]. This suggests that aldosterone may induce in part actions usually attributed to direct effects of Ang II in the vasculature.

\section{New Biomarkers of Vascular Damage}

Several studies indicate that the microparticles of endothelial origin may be considered as biomarkers of vascular dysfunction. Microparticles are small vesicular fragments $(<1 \mu \mathrm{m})$ of cellular membranes derived from most cell types including endothelial and inflammatory cells. They are released in response to activation, injury, and apoptosis [81]. Microparticles circulate in the plasma of healthy individuals, and their levels increase in cardiovascular and atherothrombotic diseases [82]. Microparticles may contribute to vascular disease progression in hypertension. In patients with severe hypertension plasma levels of microparticles correlated with systolic and diastolic blood pressure [83]. In patients with diabetes, endothelial microparticle levels are a strong predictor of myocardial infarction and correlate with arterial stiffness and endothelium-mediated vasodilation [84, 85]. They also relate to the extent and severity of coronary stenosis in patients with coronary syndromes [86]. In vitro endothelial microparticles are released in response to inflammatory stimuli [87] (including TNF- $\alpha$, thrombin, uremic toxins, ROS, and PAI-1). Although the precise mechanism leading to generation of microparticles from endothelial cells is not fully understood, there are pieces of evidences that endothelial NO synthase uncoupling and low shear stress as well [88, 89] enhance their production. Microparticles in turn may contribute in part to endothelial dysfunction itself through the activation of ROS production [90, 91]. Microparticles are capable of impairing vasorelaxation. They interfere with target cell responses by transferring chemokines and adhesion molecules to endothelial cells leading to monocyte adhesion [92] and therefore contributing to vascular injury in hypertension. Ang II may induce microparticle formation, although the evidences are controversial. Ang II type 1 receptor $\left(\mathrm{AT}_{1} \mathrm{R}\right)$ blockade is associated with a reduction in the number of monocyte, platelet, and endothelial cellderived microparticles in hypertensive diabetic patients [9395]. However Ang II administration in cultured HUVEC did not result in an increased microparticles formation [96].

\section{Conclusion}

Functional and structural alterations of resistance arteries are the earliest vascular alterations that may occur in hypertension. Low-grade inflammation and endothelial dysfunction are strictly associated in the development of hypertension and its complications. The activation of RAS plays a key role in the genesis of endothelial dysfunction and vascular remodeling. Ang II activates redox-sensitive pathways and promotes cell growth and inflammation, involving, in part, factors derived from microparticles and EPCs. Antihypertensive agents have been shown to partially correct the vascular remodeling and impaired endothelial function particularly of small resistance arteries in both experimental models and human hypertension. In particular antihypertensive drugs that antagonize RAS, including ACE inhibitors, ARBs, mineralocorticoid receptor antagonists, and the renin inhibitors, embody valid therapeutic tools to 
improve vascular function and reduce vascular remodeling and cardiovascular risk.

\section{References}

[1] E. L. Schiffrin, "Reactivity of small blood vessels in hypertension: relation with structural changes: state of the art lecture," Hypertension, vol. 19, no. 2, supplement, pp. II1-II9, 1992.

[2] E. L. Schiffrin, "Resistance arteries as endpoints in hypertension," Blood Pressure, Supplement, vol. 6, no. 2, supplement, pp. S24-S30, 1997.

[3] P. M. Vanhoutte, H. Shimokawa, E. H. C. Tang, and M. Feletou, "Endothelial dysfunction and vascular disease," Acta Physiologica, vol. 196, no. 2, pp. 193-222, 2009.

[4] C. Urbich and S. Dimmeler, "Endothelial progenitor cells: characterization and role in vascular biology," Circulation Research, vol. 95, no. 4, pp. 343-353, 2004.

[5] J. M. Hill, G. Zalos, J. P. J. Halcox et al., "Circulating endothelial progenitor cells, vascular function, and cardiovascular risk," The New England Journal of Medicine, vol. 348, no. 7, pp. 593-600, 2003.

[6] S. Durier, C. Fassot, S. Laurent et al., "Physiological genomics of human arteries: quantitative relationship between gene expression and arterial stiffness," Circulation, vol. 108, no. 15, pp. 1845-1851, 2003.

[7] Y. Yu, N. Fukuda, E. H. Yao et al., "Effects of an ARB on endothelial progenitor cell function and cardiovascular oxidation in hypertension," American Journal of Hypertension, vol. 21, no. 1, pp. 72-77, 2008.

[8] R. Ross, "Atherosclerosis-an inflammatory disease," The New England Journal of Medicine, vol. 340, pp. 115-126, 1999.

[9] A. Lerman and A. M. Zeiher, "Endothelial function: cardiac events," Circulation, vol. 111, no. 3, pp. 363-368, 2005.

[10] D. H. Endemann and E. L. Schiffrin, "Endothelial dysfunction," Journal of the American Society of Nephrology, vol. 15, no. 8, pp. 1983-1992, 2004.

[11] C. Savoia and E. L. Schiffrin, "Inflammation in hypertension," Current Opinion in Nephrology and Hypertension, vol. 15, no. 2, pp. 152-158, 2006.

[12] C. Savoia and E. L. Schiffrin, "Inhibition of the renin angiotensin system: implications for the endothelium," Current Diabetes Reports, vol. 6, no. 4, pp. 274-278, 2006.

[13] R. Kranzhöfer, J. Schmidt, C. A. H. Pfeiffer, S. Hagl, P. Libby, and W. Kübler, "Angiotensin induces inflammatory activation of human vascular smooth muscle cells," Arteriosclerosis, Thrombosis, and Vascular Biology, vol. 19, no. 7, pp. 16231629, 1999.

[14] C. De Ciuceis, F. Amiri, P. Brassard, D. H. Endemann, R. M. Touyz, and E. L. Schiffrin, "Reduced vascular remodeling, endothelial dysfunction, and oxidative stress in resistance arteries of angiotensin II-infused macrophage colonystimulating factor-deficient mice: evidence for a role in inflammation in angiotensin-induced vascular injury," Arteriosclerosis, Thrombosis, and Vascular Biology, vol. 25, no. 10, pp. 2106-2113, 2005.

[15] C. Savoia and E. L. Schiffrin, "Reduction of C-reactive protein and the use of anti-hypertensives," Vascular Health and Risk Management, vol. 3, no. 6, pp. 975-983, 2007.

[16] G. J. Blake and P. M. Ridker, "Novel clinical markers of vascular wall inflammation," Circulation Research, vol. 89, no. 9, pp. 763-771, 2001.

[17] H. D. Sesso, J. E. Buring, N. Rifai, G. J. Blake, J. M. Gaziano, and P. M. Ridker, "C-reactive protein and the risk of developing hypertension," Journal of the American Medical Association, vol. 290, no. 22, pp. 2945-2951, 2003.

[18] R. A. Preston, M. Ledford, B. J. Materson, N. M. Baltodano, A. Memon, and A. Alonso, "Effects of severe, uncontrolled hypertension on endothelial activation: soluble vascular cell adhesion molecule-1, soluble intercellular adhesion molecule1 and von Willebrand Factor," Journal of Hypertension, vol. 20, no. 5, pp. 871-877, 2002.

[19] G. J. Blake, N. Rifai, J. E. Buring, and P. M. Ridker, "Blood pressure, C-reactive protein, and risk of future cardiovascular events," Circulation, vol. 108, no. 24, pp. 2993-2999, 2003.

[20] B. Thorand, H. Löwel, A. Schneider et al., "C-reactive protein as a predictor for incident diabetes mellitus among middleaged men: results from the MONICA Augsburg Cohort Study, 1984-1998," Archives of Internal Medicine, vol. 163, no. 1, pp. 93-99, 2003.

[21] P. Libby, "Current concepts of the pathogenesis of the acute coronary syndromes," Circulation, vol. 104, no. 3, pp. 365-372, 2001.

[22] E. L. Schiffrin, "Remodeling of resistance arteries in essential hypertension and effects of antihypertensive treatment," American Journal of Hypertension, vol. 17, no. 12, pp. 11921200, 2004.

[23] E. N. T. P. Bakker, E. T. van der Meulen, B. M. van den Berg, V. Everts, J. A. E. Spaan, and E. Vanbavel, "Inward remodeling follows chronic vasoconstriction in isolated resistance arteries," Journal of Vascular Research, vol. 39, no. 1, pp. 12-20, 2002.

[24] E. L. Schiffrin and R. M. Touyz, "From bedside to bench to bedside: role of renin-angiotensin-aldosterone system in remodeling of resistance arteries in hypertension," American Journal of Physiology, vol. 287, no. 2, pp. H435-H446, 2004.

[25] E. L. Schiffrin, "Vascular stiffening and arterial compliance: implications for systolic blood pressure," American Journal of Hypertension, vol. 17, no. 12, pp. S39-S48, 2004.

[26] B. S. Wung, J. J. Cheng, Y. J. Chao, J. Lin, Y. J. Shyy, and D. L. Wang, "Cyclical strain increases monocyte chemotactic protein-1 secretion in human endothelial cells," American Journal of Physiology, vol. 270, no. 4, pp. H1462-H1468, 1996.

[27] E. L. Schiffrin, "T Lynphocytes: a role in hypertension?" Current Opinion in Nephrology and Hypertension, vol. 19, pp. 181-186, 2010.

[28] J. I. Barzilay, D. Peterson, M. Cushman et al., "The relationship of cardiovascular risk factors to microalbuminuria in older adults with or without diabetes mellitus or hypertension: the cardiovascular health study," American Journal of Kidney Diseases, vol. 44, no. 1, pp. 25-34, 2004.

[29] C. U. Chae, R. T. Lee, N. Rifai, and P. M. Ridker, "Blood pressure and inflammation in apparently healthy men," Hypertension, vol. 38, no. 3, pp. 399-403, 2001.

[30] G. Engström, L. Janzon, G. Berglund et al., "Blood pressure increase and incidence of hypertension in relation to inflammation-sensitive plasma proteins," Arteriosclerosis, Thrombosis, and Vascular Biology, vol. 22, no. 12, pp. 20542058, 2002.

[31] J. S. Yudkin, C. D. A. Stehouwer, J. J. Emeis, and S. W. Coppack, "C-reactive protein in healthy subjects: associations with obesity, insulin resistance, and endothelial dysfunction: a potential role for cytokines originating from adipose tissue?" Arteriosclerosis, Thrombosis, and Vascular Biology, vol. 19, no. 4, pp. 972-978, 1999.

[32] P. M. Ridker, M. Cushman, M. J. Stampfer, R. P. Tracy, and C. H. Hennekens, "Inflammation, aspirin, and the risk of cardiovascular disease in apparently healthy men," The New 
England Journal of Medicine, vol. 336, no. 14, pp. 973-979, 1997.

[33] P. M. Ridker, J. E. Buring, J. Shih, M. Matias, and C. H. Hennekens, "Prospective study of C-reactive protein and the risk of future cardiovascular events among apparently healthy women," Circulation, vol. 98, no. 8, pp. 731-733, 1998.

[34] T. J. Guzik, N. E. Hoch, K. A. Brown et al., "Role of the T cell in the genesis of angiotensin II-induced hypertension and vascular dysfunction," Journal of Experimental Medicine, vol. 204, no. 10, pp. 2449-2460, 2007.

[35] P. J. Marvar, S. R. Thabet, T. J. Guzik et al., "Central and peripheral mechanisms of T-lymphocyte activation and vascular inflammation produced by angiotensin II-induced hypertension," Circulation Research, vol. 107, no. 2, pp. 263-270, 2010.

[36] H. E. Lob, P. J. Marvar, T. J. Guzik et al., "Induction of hypertension and peripheral inflammation by reduction of extracellular superoxide dismutase in the central nervous system," Hypertension, vol. 55, no. 2, pp. 277-283, 2010.

[37] E. C. Viel, C. A. Lemarié, K. Benkirane, P. Paradis, and E. L. Schiffrin, "Immune regulation and vascular inflammation in genetic hypertension," American Journal of Physiology, vol. 298, no. 3, pp. H938-H944, 2010.

[38] B. Lassegue and R. E. Clepmpus, "NAD $(\mathrm{P}) \mathrm{H}$ oxidase: specific features, expression and regulation," American Journal of Physiology, vol. 285, pp. R277-R297, 2003.

[39] R. M. Touyz and E. L. Schiffrin, "Reactive oxygen species in vascular biology: implications in hypertension," Histochemistry and Cell Biology, vol. 122, no. 4, pp. 339-352, 2004.

[40] R. M. Touyz, G. Yao, and E. L. Schiffrin, "c-Src induces phosphorylation and translocation of $\mathrm{p} 47$ phox: role in superoxide generation by angiotensin II in human vascular smooth muscle cells," Arteriosclerosis, Thrombosis, and Vascular Biology, vol. 23, no. 6, pp. 981-987, 2003.

[41] T. Fukui, N. Ishizaka, S. Rajagopalan et al., "p22phox mRNA expression and NADPH oxidase activity are increased in aortas from hypertensive rats," Circulation Research, vol. 80, no. 1, pp. 45-51, 1997.

[42] K. K. Griendling, D. Sorescu, B. Lassègue, and M. UshioFukai, "Modulation of protein kinase activity and gene expression by reactive oxygen species and their role in vascular physiology and pathophysiology," Arteriosclerosis, Thrombosis, and Vascular Biology, vol. 20, no. 10, pp. 2175-2183, 2000.

[43] R. M. Touyz, X. Chen, F. Tabet et al., "Expression of a functionally active gp91phox-containing neutrophil-type $\mathrm{NAD}(\mathrm{P}) \mathrm{H}$ oxidase in smooth muscle cells from human resistance arteries: regulation by angiotensin II," Circulation Research, vol. 90, no. 11, pp. 1205-1213, 2002.

[44] N. Kalinina, A. Agrotis, E. Tararak et al., "Cytochrome b558dependent $\mathrm{NAD}(\mathrm{P}) \mathrm{H}$ oxidase-phox units in smooth muscle and macrophages of atherosclerotic lesions," Arteriosclerosis, Thrombosis, and Vascular Biology, vol. 22, no. 12, pp. 20372043, 2002.

[45] R. M. Touyz and E. L. Schiffrin, "Signal transduction mechanisms mediating the physiological and pathophysiological actions of angiotensin II in vascular smooth muscle cells," Pharmacological Reviews, vol. 52, no. 4, pp. 639-672, 2000.

[46] S. Rajagopalan, S. Kurz, T. Münzel et al., "Angiotensin IImediated hypertension in the rat increases vascular superoxide production via membrane NADH/NADPH oxidase activation: contribution to alterations of vasomotor tone," Journal of Clinical Investigation, vol. 97, no. 8, pp. 1916-1923, 1996.

[47] O. Jung, S. L. Marklund, H. Geiger, T. Pedrazzini, R. Busse, and R. P. Brandes, "Extracellular superoxide dismutase is a major determinant of nitric oxide bioavailability: in vivo and ex vivo evidence from ecSOD-deficient mice," Circulation Research, vol. 93, no. 7, pp. 622-629, 2003.

[48] R. M. Touyz, F. Tabet, and E. L. Schiffrin, "Redox-dependent signalling by angiotensin II and vascular remodelling in hypertension," Clinical and Experimental Pharmacology and Physiology, vol. 30, no. 11, pp. 860-866, 2003.

[49] E. L. Schiffrin and R. M. Touyz, "Inflammation and vascular hypertrophy induced by angiotensin II: role of NADPH oxidase-derived reactive oxygen species independently of blood pressure elevation?" Arteriosclerosis, Thrombosis, and Vascular Biology, vol. 23, no. 5, pp. 707-709, 2003.

[50] S. Sarkar, E. Vellaichamy, D. Young, and S. Sen, "Influence of cytokines and growth factors in ANG II-mediated collagen upregulation by fibroblasts in rats: role of myocytes," American Journal of Physiology, vol. 287, no. 1, pp. H107-H117, 2004.

[51] C. Satoh, N. Fukuda, W. Y. Hu, M. Nakayama, H. Kishioka, and K. Kanmatsuse, "Role of endogenous angiotensin II in the increased expression of growth factors in vascular smooth muscle cells from spontaneously hypertensive rats," Journal of Cardiovascular Pharmacology, vol. 37, no. 1, pp. 108-118, 2001.

[52] M. Azhar, J. E. J. Schultz, I. Grupp et al., "Transforming growth factor beta in cardiovascular development and function," Cytokine and Growth Factor Reviews, vol. 14, no. 5, pp. 391407, 2003.

[53] A. Bobik, "Hypertension, transforming growth factor- $\beta$, angiotensin II and kidney disease," Journal of Hypertension, vol. 22, no. 7, pp. 1265-1267, 2004.

[54] G. T. Shin, S. J. Kim, K. A. Ma, H. S. Kim, and D. Kim, "ACE inhibitors attenuate expression of renal transforming growth factor- $\beta 1$ in humans," American Journal of Kidney Diseases, vol. 36, no. 5, pp. 894-902, 2000.

[55] Q. N. Diep, F. Amiri, R. M. Touyz et al., "PPAR $\alpha$ activator effects on Ang II-induced vascular oxidative stress and inflammation," Hypertension, vol. 40, no. 6, pp. 866-871, 2002.

[56] S. M. Haffner, A. S. Greenberg, W. M. Weston, H. Chen, K. Williams, and M. I. Freed, "Effect of rosiglitazone treatment on nontraditional markers of cardiovascular disease in patients with type 2 diabetes mellitus," Circulation, vol. 106, no. 6, pp. 679-684, 2002.

[57] D. M. Tham, B. Martin-McNulty, Y. X. Wang et al., "Angiotensin II is associated with activation of NF- $\kappa \mathrm{B}$-mediated genes and downregulation of PPARs," Physiological Genomics, vol. 11, pp. 21-30, 2003.

[58] C. Qian, R. G. Schoemaker, W. H. van Gilst, and A. J. M. Roks, "The role of the renin-angiotensin-aldosterone system in cardiovascular progenitor cell function," Clinical Science, vol. 116, no. 4, pp. 301-314, 2009.

[59] T. Imanishi, T. Hano, and I. Nishio, "Angiotensin II accelarates endothelial progenitor cell senescence through induction of oxidative stress," Journal of Hypertension, vol. 23, no. 1, pp. 97104, 2005.

[60] T. Yin, X. Ma, L. Zhao, K. Cheng, and H. Wang, "Angiotensin II promotes NO production, inhibits apoptosis and enhances adhesion potential of bone marrow-derived endothelial progenitor cells," Cell Research, vol. 18, no. 7, pp. 792-799, 2008.

[61] G. Salguero, E. Akin, C. Templin et al., "Renovascular hypertension by two-kidney one-clip enhances endothelial progenitor cell mobilization in a p47phox-dependent manner," Journal of Hypertension, vol. 26, no. 2, pp. 257-268, 2008.

[62] K. Kobayashi, T. Imanishi, and T. Akasaka, "Endothelial progenitor cell differentiation and senescence in an angiotensin 
II-infusion rat model," Hypertension Research, vol. 29, no. 6, pp. 449-455, 2006.

[63] T. Imanishi, T. Hano, and I. Nishio, "Angiotensin II potentiates vascular endothelial growth factor-induced proliferation and network formation of endothelial progenitor cells," Hypertension Research, vol. 27, no. 2, pp. 101-108, 2004.

[64] J. Kähler, A. Ewert, J. Weckmüller et al., "Oxidative stress increases endothelin-1 synthesis in human coronary artery smooth muscle cells," Journal of Cardiovascular Pharmacology, vol. 38, no. 1, pp. 49-57, 2001.

[65] L. Li, G. D. Fink, S. W. Watts et al., "Endothelin-1 increases vascular superoxide via endothelinA-NADPH oxidase pathway in low-renin hypertension," Circulation, vol. 107, no. 7, pp. 1053-1058, 2003.

[66] M. Iglarz, R. M. Touyz, F. Amiri, M. F. Lavoie, Q. N. Diep, and E. L. Schiffrin, "Effect of peroxisome proliferatoractivated receptor- $\alpha$ and $-\gamma$ activators on vascular remodeling in endothelin-dependent hypertension," Arteriosclerosis, Thrombosis, and Vascular Biology, vol. 23, no. 1, pp. 45-51, 2003.

[67] F. Amiri, A. Virdis, M. Fritsch Neves et al., "Endotheliumrestricted overexpression of human endothelin-1 causes vascular remodeling and endothelial dysfunction," Circulation, vol. 110, no. 15, pp. 2233-2240, 2004.

[68] D. N. Muller, E. M. A. Mervaala, F. Schmidt et al., "Effect of bosentan on $\mathrm{nf}-\kappa \mathrm{b}$, inflammation, and tissue factor in angiotensin II-induced end-organ damage," Hypertension, vol. 36, no. 2, pp. 282-290, 2000.

[69] R. M. Touyz, G. Yao, E. Viel, F. Amiri, and E. L. Schiffrin, "Angiotensin II and endothelin-1 regulate MAP kinases through different redox-dependent mechanisms in human vascular smooth muscle cells," Journal of Hypertension, vol. 22, no. 6, pp. 1141-1149, 2004.

[70] Q. Pu, M. F. Neves, A. Virdis, R. M. Touyz, and E. L. Schiffrin, "Endothelin antagonism on aldosterone-induced oxidative stress and vascular remodeling," Hypertension, vol. 42, no. 1, pp. 49-55, 2003.

[71] T. J. L. Vuurmans, P. Boer, and H. A. Koomans, "Effects of endothelin-1 and endothelin-1 receptor blockade on cardiac output, aortic pressure, and pulse wave velocity in humans," Hypertension, vol. 41, no. 6, pp. 1253-1258, 2003.

[72] C. M. McEniery, A. Qasem, M. Schmitt, A. P. Avolio, J. R. Cockcroft, and I. B. Wilkinson, "Endothelin-1 regulates arterial pulse wave velocity in vivo," Journal of the American College of Cardiology, vol. 42, no. 11, pp. 1975-1981, 2003.

[73] E. Harada, M. Yoshimura, H. Yasue et al., "Aldosterone induces angiotensin-converting-enzyme gene expression in cultured neonatal rat cardiocytes," Circulation, vol. 104, no. 2, pp. 137139, 2001.

[74] E. L. Schiffrin, J. Gutkowska, and J. Genest, "Effect of angiotensin II and deoxycorticosterone infusion on vascular angiotensin II receptors in rats," American Journal of Physiology, vol. 15, no. 4, pp. H608-H614, 1984.

[75] H. V. Joffe and G. K. Adler, "Effect of aldosterone and mineralocorticoid receptor blockade on vascular inflammation," Heart Failure Reviews, vol. 10, no. 1, pp. 31-37, 2005.

[76] J. Blanco-Rivero, V. Cachofeiro, V. Lahera et al., "Participation of prostacyclin in endothelial dysfunction induced by aldosterone in normotensive and hypertensive rats," Hypertension, vol. 46, no. 1, pp. 107-112, 2005.

[77] R. Rocha, P. N. Chander, K. Khanna, A. Zuckerman, and C. T. Stier, "Mineralocorticoid blockade reduces vascular injury in stroke-prone hypertensive rats," Hypertension, vol. 31, no. 1, pp. 451-458, 1998.
[78] A. Fiebeler, F. Schmidt, D. N. Müller et al., "Mineralocorticoid receptor affects $\mathrm{AP}-1$ and nuclear factor $\kappa \mathrm{B}$ activation in angiotensin II-induced cardiac injury," Hypertension, vol. 37, no. 2, pp. 787-793, 2001.

[79] F. Z. Ammarguellat, P. O. Gannon, F. Amiri, and E. L. Schiffrin, "Fibrosis, matrix metalloproteinases, and inflammation in the heart of DOCA-salt hypertensive rats: role of ETa receptors," Hypertension, vol. 39, no. 2, pp. 679-684, 2002.

[80] A. Virdis, M. F. Neves, F. Amiri, E. Viel, R. M. Touyz, and E. L. Schiffrin, "Spironolactone improves angiotensin-induced vascular changes and oxidative stress," Hypertension, vol. 40, no. 4, pp. 504-510, 2002.

[81] C. M. Boulanger, "Microparticles, vascular function and hypertension," Current Opinion in Nephrology and Hypertension, vol. 19, no. 2, pp. 177-180, 2010.

[82] C. M. Boulanger, N. Amabile, and A. Tedgui, "Circulating microparticles: a potential prognostic marker for atherosclerotic vascular disease," Hypertension, vol. 48, no. 2, pp. 180186, 2006.

[83] R. A. Preston, W. Jy, J. J. Jimenez et al., "Effects of severe hypertension on endothelial and platelet microparticles," Hypertension, vol. 41, no. 2, pp. 211-217, 2003.

[84] H. Koga, S. Sugiyama, K. Kugiyam et al., "Elevated levels of VE-cadherin-positive endothelial mircoparticles in patients with type 2 diabetes mellitus and coronary artery disease," Journal of the American College of Cardiology, vol. 45, pp. 16221630, 2005.

[85] K. Esposito, M. Ciotola, F. Giugliano et al., "Endothelial microparticles correlate with erectile dysfunction in diabetic men," International Journal of Impotence Research, vol. 19, no. 2, pp. 161-166, 2007.

[86] L. Bernal-Mizrachi, W. Jy, J. J. Jimenez et al., "High levels of circulating endothelial microparticles in patients with acute coronary syndromes," American Heart Journal, vol. 145, no. 6, pp. 962-970, 2003.

[87] G. N. Chironi, C. M. Boulanger, A. Simon, F. Dignat-George, J. M. Freyssinet, and A. Tedgui, "Endothelial microparticles in diseases," Cell and Tissue Research, vol. 335, no. 1, pp. 143-151, 2009.

[88] J. M. Wang, Y. Wang, J. Y. Huang et al., "C-reactive proteininduced endothelial microparticle generation in HUVECs is related to BH4-dependent NO formation," Journal of Vascular Research, vol. 44, no. 3, pp. 241-248, 2007.

[89] C. M. Boulanger, N. Amabile, A. P. Guérin et al., "In vivo shear stress determines circulating levels of endothelial microparticles in end-stage renal disease," Hypertension, vol. 49, no. 4, pp. 902-908, 2007.

[90] N. Amabile, A. P. Guérin, A. Leroyer et al., "Circulating endothelial microparticles are associated with vascular dysfunction in patients with end-stage renal failure," Journal of the American Society of Nephrology, vol. 16, no. 11, pp. 3381-3388, 2005.

[91] S. V. Brodsky, F. Zhang, A. Nasjletti, and M. S. Goligorsky, "Endothelium-derived microparticles impair endothelial function in vitro," American Journal of Physiology, vol. 286, no. 5, pp. H1910-H1915, 2004.

[92] S. F. Mause, P. von Hundelshausen, A. Zernecke, R. R. Koenen, and C. Weber, "Platelet microparticles: a transcellular delivery system for RANTES promoting monocyte recruitment on endothelium," Arteriosclerosis, Thrombosis, and Vascular Biology, vol. 25, no. 7, pp. 1512-1518, 2005.

[93] S. Nomura, A. Shouzu, S. Omoto, M. Nishikawa, S. Fukuhara, and T. Iwasaka, "Losartan and simvastatin inhibit platelet 
activation in hypertensive patients," Journal of Thrombosis and Thrombolysis, vol. 18, no. 3, pp. 177-185, 2005.

[94] S. Nomura, A. Shouzu, S. Omoto, M. Nishikawa, S. Fukuhara, and T. Iwasaka, "Effect of valsartan on monocyte/endothelial cell activation markers and adiponectin in hypertensive patients with type 2 diabetes mellitus," Thrombosis Research, vol. 117, no. 4, pp. 385-392, 2006.

[95] S. Nomura, A. Shouzu, S. Omoto, M. Nishikawa, and T. Iwasaka, "Effects of losartan and simvastatin on monocytederived microparticles in hypertensive patients with and without type 2 diabetes mellitus," Clinical and Applied Thrombosis/Hemostasis, vol. 10, no. 2, pp. 133-141, 2004.

[96] M. Labiós, M. Martinez, F. Gabriel, V. Guiral, A. Muñoz, and J. Aznar, "Effect of eprosartan on cytoplasmic free calcium mobilization, platelet activation, and microparticle formation in hypertension," American Journal of Hypertension, vol. 17, no. 9, pp. 757-763, 2004. 


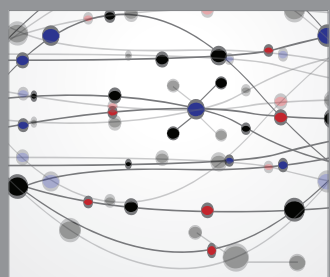

The Scientific World Journal
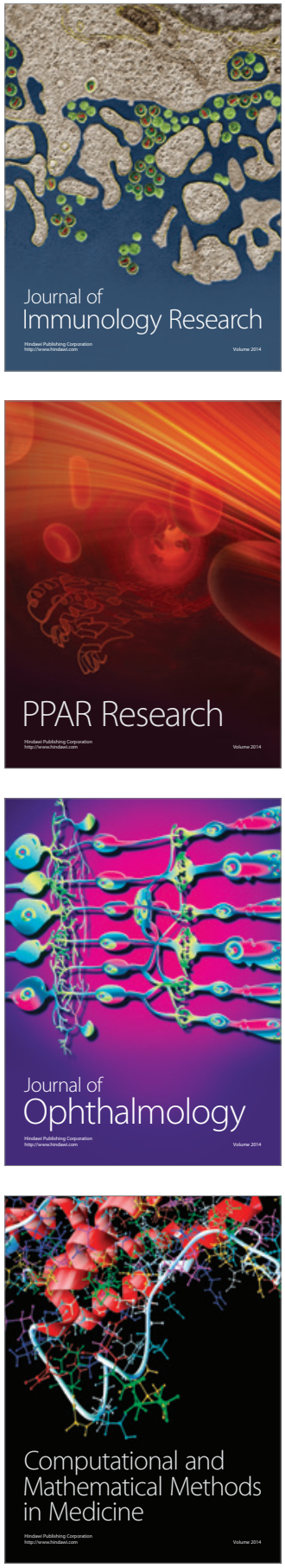

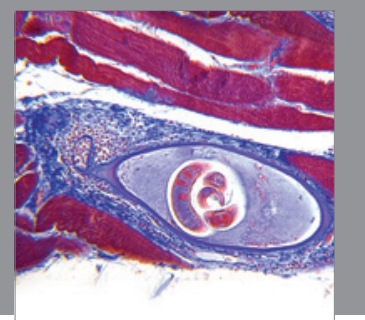

Gastroenterology

Research and Practice
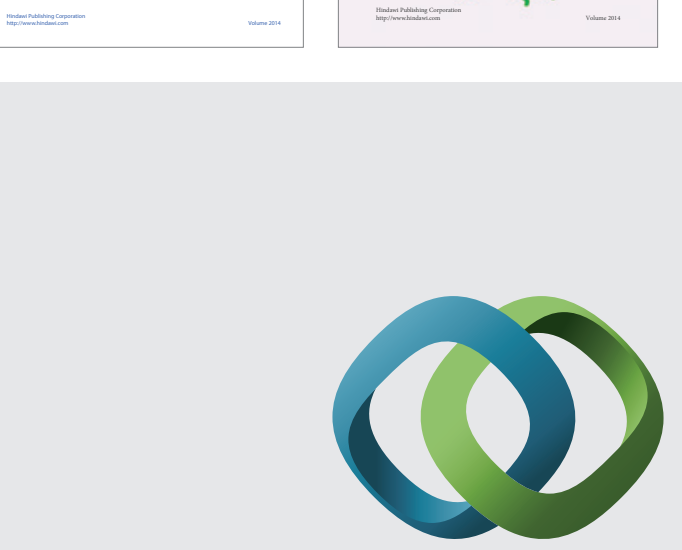

\section{Hindawi}

Submit your manuscripts at

http://www.hindawi.com
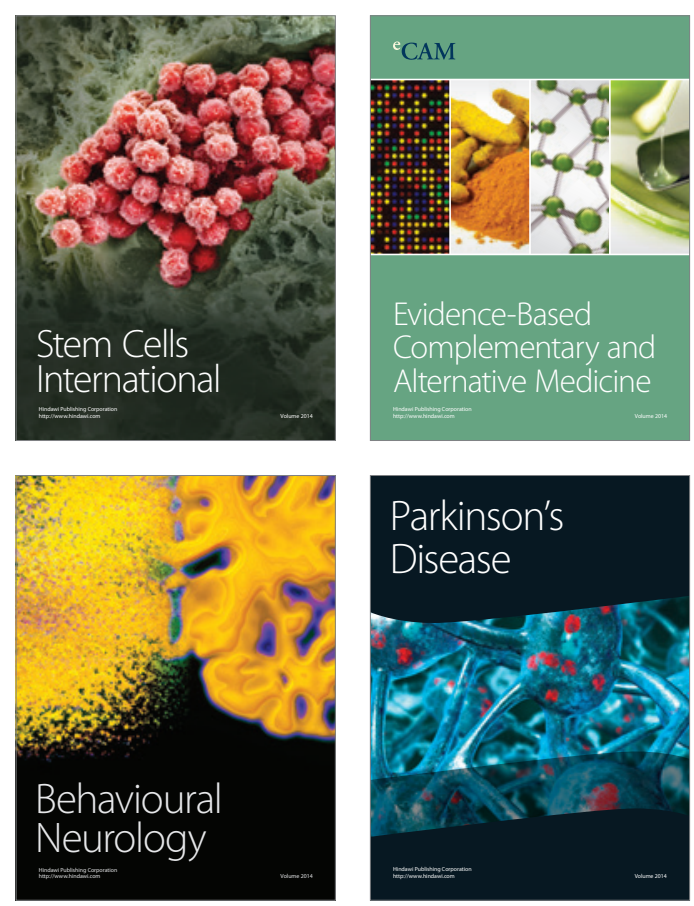

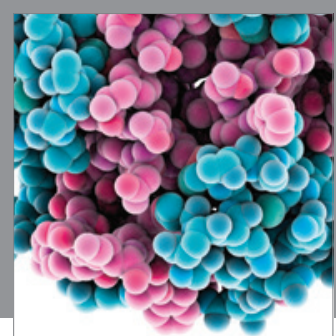

Journal of
Diabetes Research

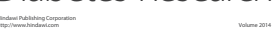

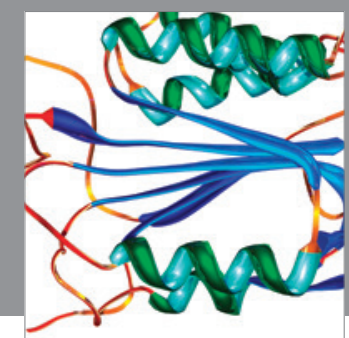

Disease Markers
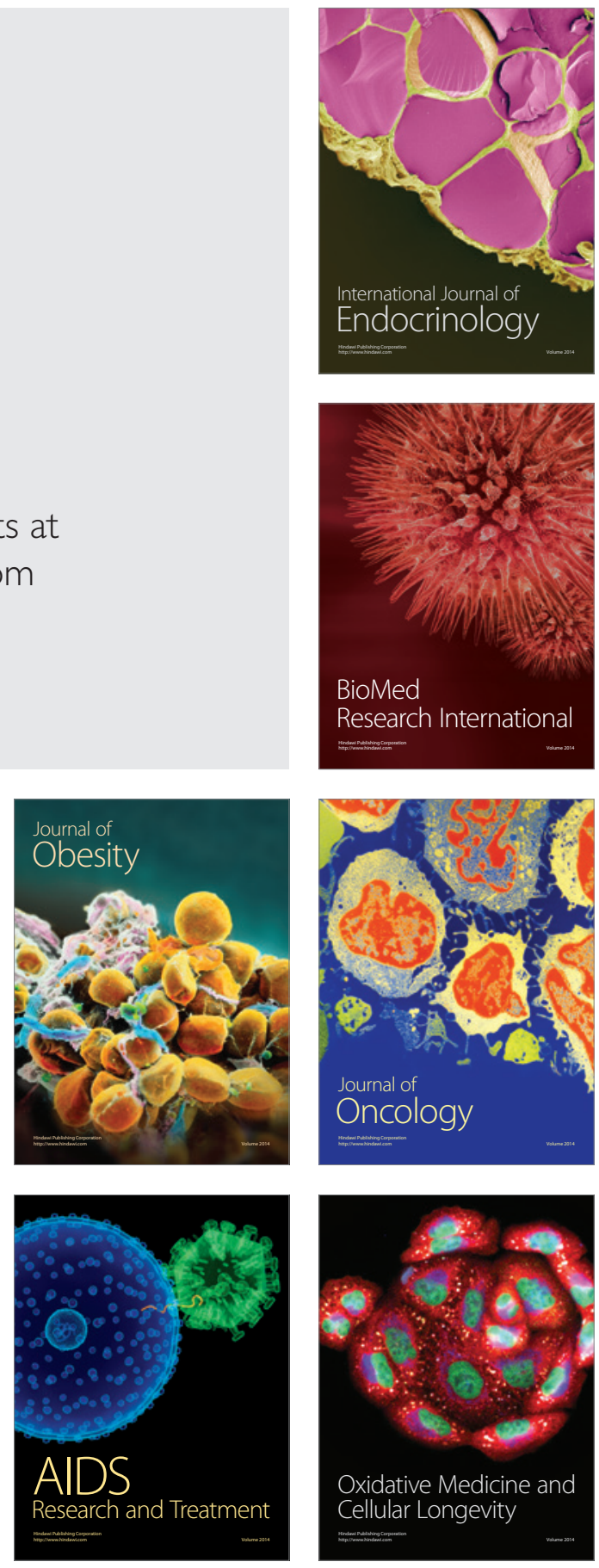